\title{
ARTICLE OPEN Citrullination mediated by PPAD constrains biofilm formation in $P$. gingivalis strain 381
}

\author{
Danielle M. Vermilyea ${ }^{1}$, Gregory K. Ottenberg ${ }^{1}$ and Mary E. Davey ${ }^{1}$
}

Porphyromonas gingivalis is the only known human-associated prokaryote that produces a peptidylarginine deiminase (PPAD), a protein-modifying enzyme that is secreted along with a number of virulence factors via a type IX secretion system (T9SS). While the function of PPAD in P. gingivalis physiology is not clear, human peptidylarginine deiminases are known to convert positively charged arginine residues within proteins to neutral citrulline and, thereby, impact protein conformation and function. Here, we report that the lack of citrullination in a PPAD deletion mutant $(\Delta 8820)$ enhances biofilm formation. More $\Delta 8820$ cells attached to the surface than the parent strain during the early stages of biofilm development and, ultimately, mature $\Delta 8820$ biofilms were comprised of significantly more cell-cell aggregates and extracellular matrix. Imaging by electron microscopy discovered that $\Delta 8820$ biofilm cells secrete copious amounts of protein aggregates. Furthermore, gingipain-derived adhesin proteins, which are also secreted by the T9SS were predicted by mass spectrometry to be citrullinated and citrullination of these targets by wild-type strain 381 in vitro was confirmed. Lastly, $\Delta 8820$ biofilms contained more gingipain-derived adhesin proteins and more gingipain activity than 381 biofilms. Overall, our findings support the model that citrullination of T9SS cargo proteins known to play a key role in colonization, such as gingipain-derived adhesin proteins, is an underlying mechanism that modulates $P$. gingivalis biofilm development.

npj Biofilms and Microbiomes (2019)5:7; https://doi.org/10.1038/s41522-019-0081-x

\section{INTRODUCTION}

Porphyromonas gingivalis, an oral bacterium primarily known for its etiological role in periodontal disease, is implicated in rheumatoid arthritis, which is a common comorbidity in periodontal disease. ${ }^{1}$ Research has shown that generation of anticitrullinated protein antibodies (ACPAs) is a key feature of rheumatoid arthritis. ${ }^{2,3}$ Interestingly, $P$. gingivalis secretes a peptidylarginine deiminase (PPAD), an enzyme that converts positively charged arginine residues to neutral citrulline residues within peptides and proteins. While humans express five different isotypes (PAD1-4 and PAD 6) that play roles in both health and disease, PPAD is the only known prokaryotic PPAD..$^{4-12}$ Currently, data support the model that citrullination of peptides or proteins by PPAD in the periodontium can lead to a breakdown in tolerance and, thereby, the production of ACPAs, and the development or progression of rheumatoid arthritis. ${ }^{2,3,5,13-17}$ Although the link to rheumatoid arthritis has driven an extensive amount of PPAD research, the role of PPAD in the basic physiology of $P$. gingivalis, in particular its impact during biofilm growth, is still unclear.

$P$. gingivalis is a metabolically atypical anaerobe that utilizes protein substrates as a primary source for energy production and growth. This requires the release of a complex array of proteolytic enzymes into its environment either through direct secretion or indirectly via the release of outer membrane vesicles (OMVs). Secretion of a number of key enzymes, including the proteases known as gingipains ( $\operatorname{RgpA}, \operatorname{RgpB}$, and $\mathrm{Kgp})$ and PPAD, is accomplished via a Type IX secretion system (T9SS). ${ }^{18}$ Although the role of PPAD in the context of periodontal disease and bacterial physiology is not clear, one model proposes that ammonia, produced as a byproduct of PPAD activity, helps $P$. gingivalis resist acidic cleansing in the mouth. ${ }^{4,6,19-24}$ This working hypothesis is strongly supported by the fact that growth of $P$. gingivalis on protein substrates is inhibited at low $\mathrm{pH}$ and citrullination in combination with amino acid fermentation, in particular deamination of lysine and arginine, could generate a highly favorable environment for survival. ${ }^{25}$ Additional research has shown that deleting the gene that encodes PPAD in encapsulated strain W50 inhibits periodontal bone loss in a $\mathrm{BALB} / \mathrm{c}$ mouse model, while deletion in the non-encapsulated, fimbriated strain ATCC 33277 impairs attachment to and invasion of primary human gingival fibroblasts. ${ }^{14,26}$ Taken together, previous findings indicate that PPAD activity impacts growth, as well as colonization, attachment, and/or invasion of host cells and tissues.

Given the fundamental importance of sessile growth (biofilm formation) to the survival and pathogenic potential of $P$. gingivalis, the goal of this study was to evaluate the effect of PPAD activity during biofilm growth and development. Reports show that $P$. gingivalis can citrullinate a variety of endogenous proteins known to play a role in biofilm formation including a subunit of the major fimbriae (FimA), a subunit of the minor fimbriae (Mfa1), and gingipains (RgpA and Kgp), but the effect of citrullinating these proteins on biofilm development is unclear. ${ }^{7}$ Furthermore, citrullination of free L-arginine in $P$. gingivalis culture by other bacterial arginine deiminases results in the downregulation of fimbriae and subsequent biofilm formation. ${ }^{27-29}$ Although the biofilm-forming strain of $P$. gingivalis used in this study does not

${ }^{1}$ Department of Oral Biology, College of Dentistry, University of Florida, Gainesville, FL, USA

Correspondence: Mary E. Davey (mdavey@dental.ufl.edu)

Received: 12 September 2018 Accepted: 15 January 2019

Published online: 07 February 2019 


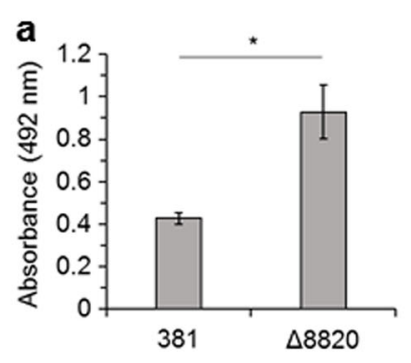

C

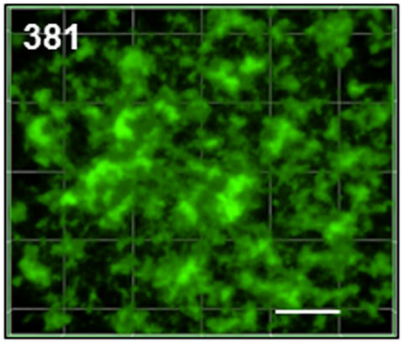

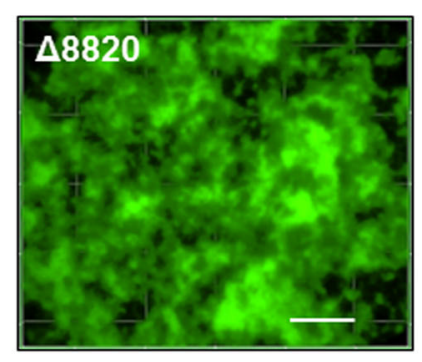

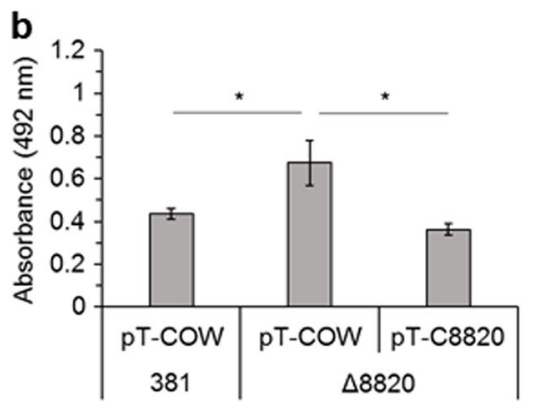

d
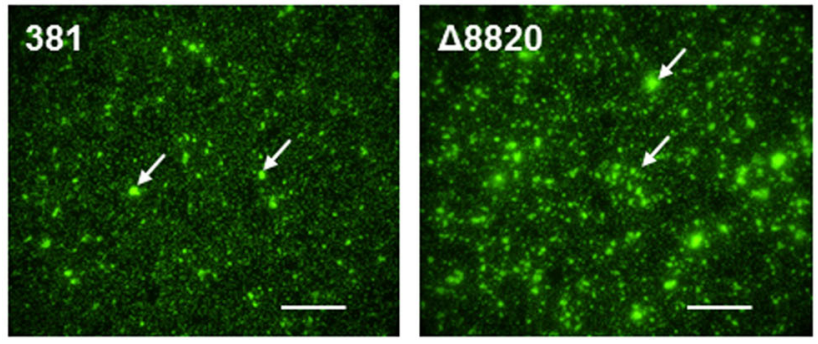

Fig. 1 Deletion of the gene encoding PPAD enhances biofilm formation. a 381 and $\Delta 8820$ biomass after $24 \mathrm{~h}$ was quantified by staining with safranin. b $24 \mathrm{~h}$ biomass of empty vector controls (381 pT-COW and $\Delta 8820$ pT-COW) and complemented $\Delta 8820$ ( $\Delta 8820$ pT-C8820) was quantified by staining with safranin. Data in $\mathbf{a}$ and $\mathbf{b}$ are averages of three independent experiments $(n=9)$. Error bars represent the standard deviation. The data in a were analyzed using the Student's two-tailed $t$-test. The data in $\mathbf{b}$ were analyzed by ANOVA with Bonferroni post tests. ${ }^{*} p<0.05$. c Top-down view of $24 \mathrm{~h}$ biofilms stained with SYTO 9 and propidium iodide. $\mathbf{d}$ Attached cells $2 \mathrm{~h}$ after setting up a biofilm assay stained with SYTO 9 and propidium iodide. Arrows indicate examples of cell-cell aggregates. Scale bar: $50 \mu \mathrm{m}$

have an arginine deiminase, PPAD can citrullinate both peptidylarginine and, to a lesser extent, free L-arginine. ${ }^{20,23}$ Therefore, we hypothesized that PPAD modulates biofilm growth and development by citrullination of peptidylarginine within proteins and/or by regulating the availability of free L-arginine, either directly or indirectly.

To accomplish our goals, we deleted the gene that encodes PPAD in strain 381 (a highly fimbriated and robust biofilm-forming strain that is closely related to strain ATCC 33277, but hyperfimbriated) and investigated the effect of a lack of citrullination on biofilm development. Our analysis discovered that the mutant strain has an enhanced biofilm phenotype resulting in two-fold more biomass. To begin to elucidate the underlying mechanism(s) for this phenotype, we employed different growth conditions along with western analysis, fluorescence microscopy, and electron microscopy (EM). Our studies revealed that the PPAD mutant $(\triangle 8820)$ secretes copious amounts of protein aggregates and it generates a distinct biofilm architecture; unlike the parent strain, $\Delta 8820$ biofilm cells are encased in an extensive lattice-like structure of extracellular matrix. Overall, our findings support the model that citrullination of secreted T9SS cargo proteins, in particular gingipain-derived adhesins, impacts the release and localization of these proteins, which in turn alters cell-cell interactions and biofilm matrix development.

\section{RESULTS}

Deletion of PGF_00008820, the gene encoding PPAD in strain 381, enhances biofilm formation

Previous findings show that removal of free L-arginine from the environment by arginine deiminases inhibits biofilm formation of $P$. gingivalis, while addition of L-arginine can enhance attachment. ${ }^{27-29}$ Although these findings are specific to free L-arginine, they demonstrate the importance of L-arginine in and the impact of arginine deiminases on $P$. gingivalis biofilm formation. Therefore, we hypothesized that deletion of the gene encoding PPAD, a
PPAD, in hyperfimbriated strain 381 would affect peptidylarginine and/or L-arginine availability and, thereby, biofilm formation. To test this hypothesis, we first generated a PPAD deletion mutant in strain $381(\Delta 8820)$, confirmed the depletion of enzymatic activity by colorimetric assay, and determined that there was no change in growth rate (Supplementary Figures 1 and 3). We measured biofilm formation by safranin staining and found that the PPAD deletion mutant had an enhanced biofilm phenotype with an average absorbance at $492 \mathrm{~nm}\left(A_{492}\right)$ of $0.93 \pm 0.13$ compared to an $A_{492}$ of $0.43 \pm 0.03$ for the wild type (Fig. 1a). We then complemented strain $\Delta 8820$ in trans $(\Delta 8820$ pT-C8820) and transformed strains 381 and $\Delta 8820$ with the empty vector, pTCOW, as controls. Complementation of $\triangle 8820$ restored PPAD enzymatic activity (Supplementary Figure 2). Although complementation resulted in a greater rate of enzymatic activity in $\Delta 8820$ pT-C8820, the concentration of citrulline measured in the stationary cultures was the same in 381 pT-COW and $\Delta 8820$ pTC8820 (Supplementary Figures 2 and 3). When we measured biofilm formation, we found that the presence of the pT-COW control plasmid lowered the $A_{492}$ of $\Delta 8820$ to $0.68 \pm 0.10$ from $0.93 \pm 0.13$, but $\Delta 8820$ pT-COW biomass was still significantly greater than that of 381 pT-COW (Fig. 1b). Importantly, when the deletion mutant was complemented, biofilm formation was restored to wild-type levels (Fig. 1b). Overall, these findings show that deletion of the gene encoding PPAD in strain 381 enhances biofilm formation, while expression of PPAD inhibits biofilm development.

Biofilm architecture was characterized by staining with SYTO 9 to stain all bacterial cells and propidium iodide to stain only dead cells. Fluorescence microscopy confirmed that $\Delta 8820$ biofilms were comprised of more biomass than 381 biofilms (Fig. 1c, 2d). Additionally, $\Delta 8820$ biofilms had larger microcolonies with less void space between them (Fig. 1c). We also examined surface attachment by cells during the early stages of biofilm development. Two hours after setting up the static biofilm assay, wells were washed and attached cells were examined by staining with SYTO 9 and propidium iodide. Compared to cell attachment by 
a
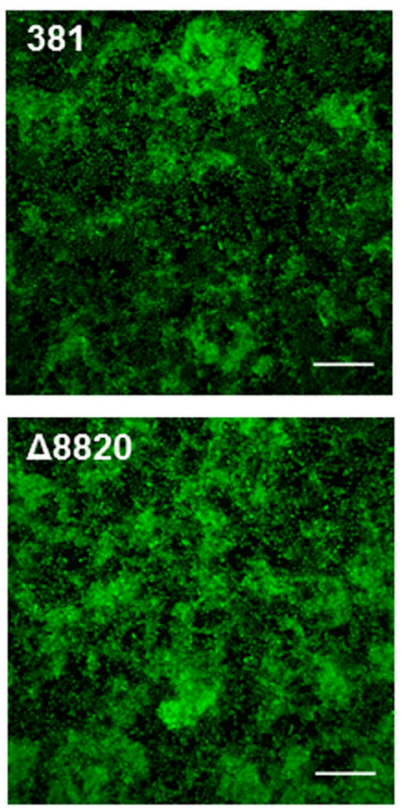

b

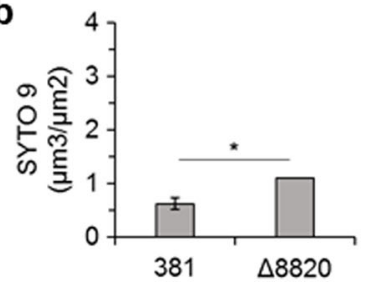

SYPRO Ruby
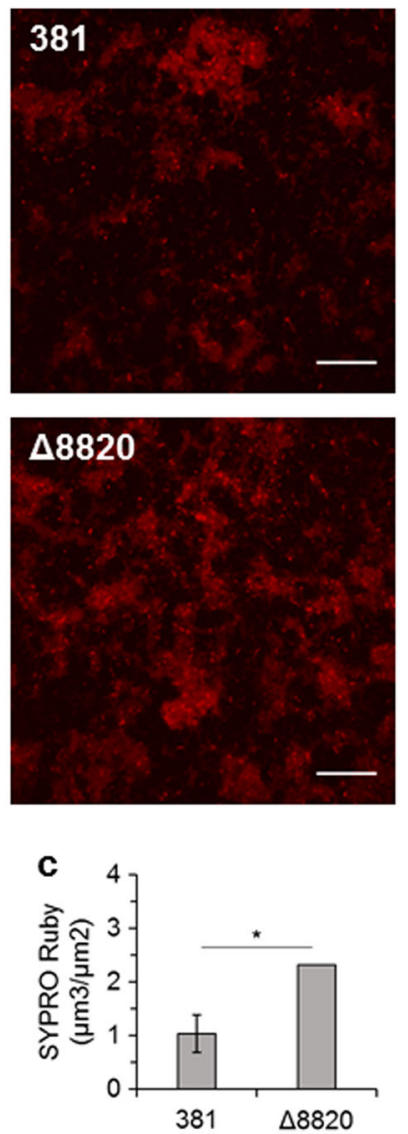

Merged
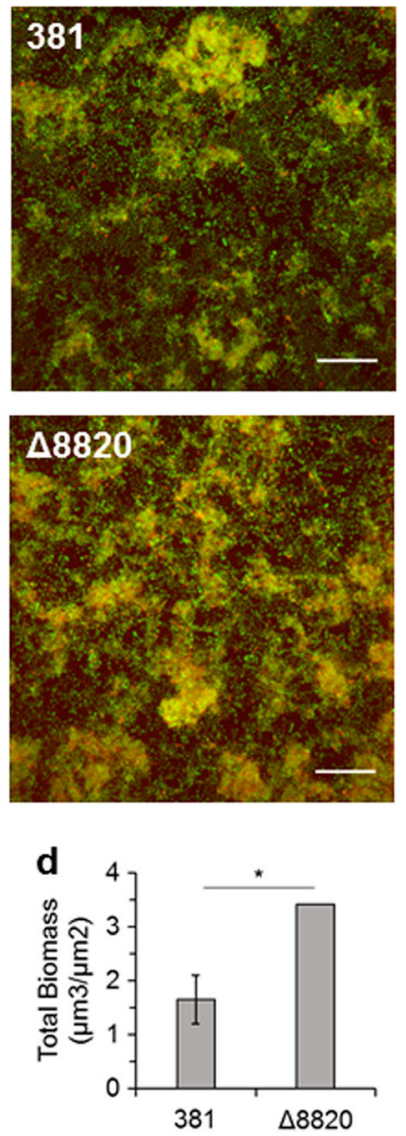

Fig. $2 \Delta 8820$ biofilms are comprised of more bacterial cells and protein than 381 biofilms. a 381 and $\Delta 8820$ were grown for $24 \mathrm{~h}$ on glass, stained with SYTO 9 (cells) and SYPRO Ruby (extracellular protein), and images were acquired by CLSM. Images are a top-down view of stacked maximum intensity projection images. Scale bar: $20 \mu \mathrm{m}$. b SYTO 9, c SYPRO Ruby, and d total biomass were quantified using Comstat2. Data are averages of two replicates $(n=2)$. Error bars represent the standard deviation. The data were analyzed using the Student's two-tailed $t$-test. ${ }^{*} p<0.05$

strain 381 , more $\Delta 8820$ cells attached to the well subsurface as punctate aggregates (Fig. 1d). No differences in viability were observed between 381 and $\Delta 8820$. Biofilm composition was also evaluated by staining with SYTO 9 and SYPRO Ruby (extracellular protein detection). The biomass of $\Delta 8820$ biofilms was comprised of more cells and more protein (Fig. 2b-d). The ratio of extracellular protein to cells (SYPRO Ruby to SYTO 9) was $1.62 \pm$ 0.28 for 381 and $2.11 \pm 0$ for $\Delta 8820$, indicating that $\Delta 8820$ biofilms contained more extracellular protein per cell, thereby, suggesting a defect in the release of proteins into the surroundings. Taken together, the data indicate that the enhanced biofilm phenotype of the PPAD deletion mutant is due to greater cell-cell interactions and attachment in conjunction with greater accumulation of cell surface and biofilm matrix protein.

Deletion of the gene encoding PPAD results in increased matrix production

Localization of PPAD and PPAD enzymatic activity has been examined in several strains of $P$. gingivalis. ${ }^{4,7}, 8$ To examine the localization of PPAD enzymatic activity in strain 381, we measured enzymatic activity associated with the cell surface and the supernatant using a colorimetric assay. The majority of enzymatic activity, $69 \pm 5.4 \%$, in 381 was cell-surface associated, while $31 \pm$ $5.4 \%$ was associated with the supernatant (Supplementary Figure 4a). These results were in line with previous findings for other strains of $P$. gingivalis. ${ }^{4}$ Although the majority of enzymatic activity was cell associated, almost all of the citrulline that was detectable using the colorimetric assay was found in the supernatant after 24-36 h (Supplementary Figure 4b). Therefore, our findings implicated secreted or extracellular proteins as substrates of PPAD in monoculture. Next, we performed transmission electron microscopy (TEM) of negatively stained cells to investigate and characterize the surface structures and extracellular environment of 381 and $\Delta 8820$ cells from colony biofilms grown on blood agar plates. TEM revealed that $\Delta 8820$ samples produced an abundance of negatively stained extracellular substance that was not present in 381 samples (Fig. 3). Upon closer observation, the surface of mutant cells was decorated by this substance, which extended from the cell surface as fibers (Fig. 3b, c). Further, the fibers were capable of forming a meshwork around mutant cells and appeared to extrude from discrete cell surface sites (Fig. 3c). Since uranyl acetate primarily binds lipids and proteins, and PPAD activity is tightly linked to secretion of T9SS cargo proteins, our working hypothesis was that the extracellular substance produced by $\Delta 8820$ was composed of protein and that the enhanced biofilm phenotype of $\Delta 8820$ was due, in part, to greater matrix production. To investigate this hypothesis, we performed cryo scanning electron microscopy (Cryo-SEM) on colony biofilms grown on blood agar plates in order to retain the conformation of the biofilms. 381 colony biofilms contained easily identifiable bacterial cells (Fig. 4 , top). In contrast, $\Delta 8820$ colony biofilms had a smooth, dimpled surface and cells within these biofilms were coated with or encased in a matrix-like substance (Fig. 4, bottom). 

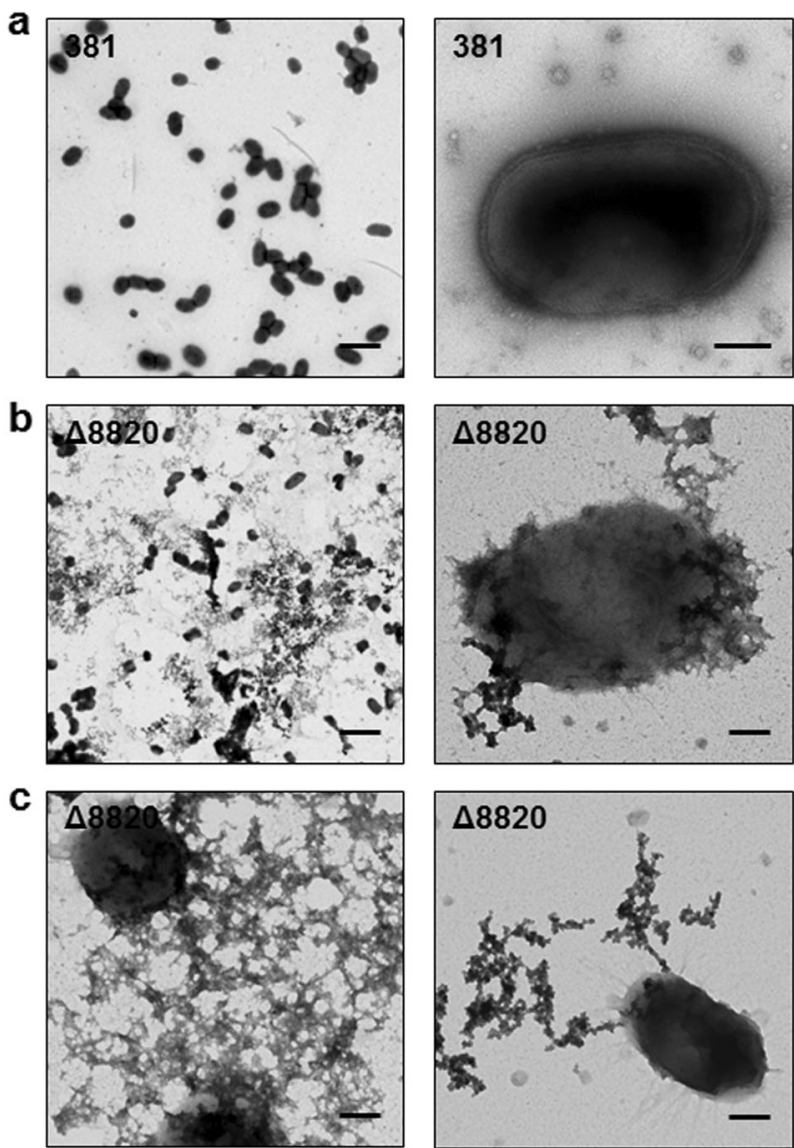

Fig. $3 \Delta 8820$ cells produce a surface-associated extracellular substance that is not present on 381 cells. Bacterial cells from a 381 and $\mathbf{b}, \mathbf{c} \Delta 8820$ colony biofilms grown on plates were negatively stained with $0.5 \%$ aqueous uranyl acetate and then imaged by TEM. a 381 displayed typical cell morphology. Scale bar: (left) $2 \mu \mathrm{m}$ and (right) $200 \mathrm{~nm}$. b $\Delta 8820$ cells were (left) surrounded by and (right) coated with an extracellular substance that could be stained by uranyl acetate. Scale bar: (left) $2 \mu \mathrm{m}$ and (right) $200 \mathrm{~nm}$. c The extracellular substance in $\Delta 8820$ samples was capable of (left) forming a meshwork around cells and (right) appeared to extrude from specific sites at the cell surface. Scale bar: $200 \mathrm{~nm}$
These observations support our hypothesis that deletion of PPAD alters the biofilm matrix.

The WT can citrullinate recombinant gingipain adhesin domains in vitro

Given the protein-centric physiology of $P$. gingivalis and our above findings, we hypothesized that the altered matrix of $\Delta 8820$ biofilms was composed of or due to the accumulation of secreted protein(s). Studies show that a variety of secreted proteins are predicted to be citrullinated including gingipains RgpA and Kgp, fimbriae subunits FimA and Mfa1, and other outer membrane and heme-binding proteins. ${ }^{7}$ Fimbriae are major surface structures that mediate cell-cell interactions and surface attachment in $P$. gingivalis. ${ }^{30-34}$ Studies have shown that removal of arginine from the environment by arginine deiminases inhibits fimbriae production and subsequent biofilm formation by $P$. gingivalis. ${ }^{27-}$ 29 As a result, we hypothesized that the enhanced biofilm formation by $\Delta 8820$ was due to an increase in fimbriae on the cell surface. Surprisingly, western blot analysis of both major (FimA) and minor (Mfa1) fimbriae proteins in 381 and $\Delta 8820$ biofilms showed no differences in expression (Supplementary Figure 5b). Similarly, no differences were observed between 381 and $\Delta 8820$ planktonic cell cultures (Supplementary Figure $5 c$ ). Therefore, the enhanced biofilm phenotype of the PPAD deletion mutant is not due to an increase in fimbriae on the cell surface.

In order to identify citrullinated proteins, we made attempts to use an anti-citrulline (modified) detection kit (EMD Millipore \#17347B) as previously described, but this proved unsuccessful., ${ }^{5,13,16}$ Alternatively, we analyzed stationary phase 381 and $\Delta 8820$ cell lysates by mass spectrometry to identify citrulline residues. Under the conditions tested, neither FimA nor Mfa1 were predicted to be citrullinated. However, there were two proteins in which a citrulline residue was predicted in all three 381 samples and in none of the $\Delta 8820$ samples: RgpA and Kgp (Fig. 5a, Supplementary Figure 6). RgpA and Kgp are gingipains, which are proteases that cleave at arginine residues or lysine residues, respectively. $\mathrm{RgpA}$ and Kgp are transcribed as precursor proteins containing a prodomain, the catalytic or proteolytic domain, and the adhesin domain, before ultimately being proteolytically processed and glycosylated. $^{35,36}$ The adhesin domains of RgpA and Kgp are autoprocessed into smaller adhesin proteins Rgp44, Rgp15, Rgp17, Rgp27, Kgp39, Kgp15, and Kgp44. ${ }^{36}$ Interestingly, the predicted citrulline residues were within the adhesin domains,
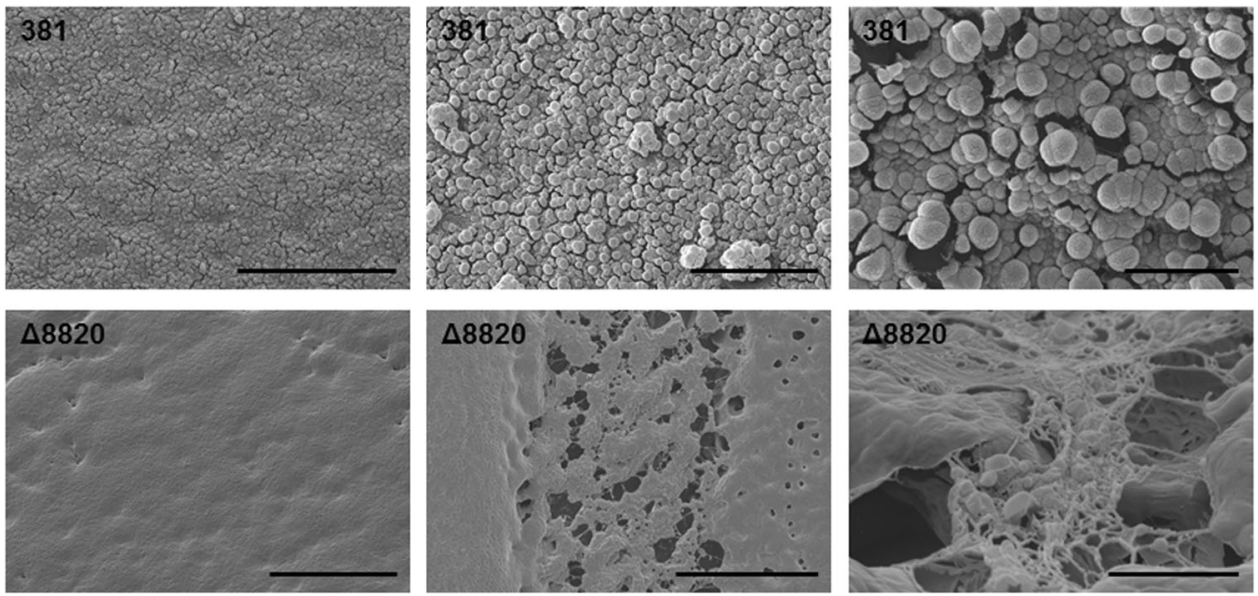

Fig. 4 Deletion of the gene encoding PPAD results in increased matrix production. 381 and $\Delta 8820$ colony biofilms grown on plates were imaged by Cryo-SEM. Bacterial cells were visible on the surface and within 381 colony biofilms. The surface of $\Delta 8820$ colony biofilms were smooth and cells within the biofilms were coated or encased in a matrix-like substance. Scale bar: (top left) $10 \mu \mathrm{m}$, (top middle) $5 \mu \mathrm{m}$, (top right) $1 \mu \mathrm{m}$, (bottom left) $20 \mu \mathrm{m}$, (bottom middle) $20 \mu \mathrm{m}$, (bottom right) $2 \mu \mathrm{m}$ 

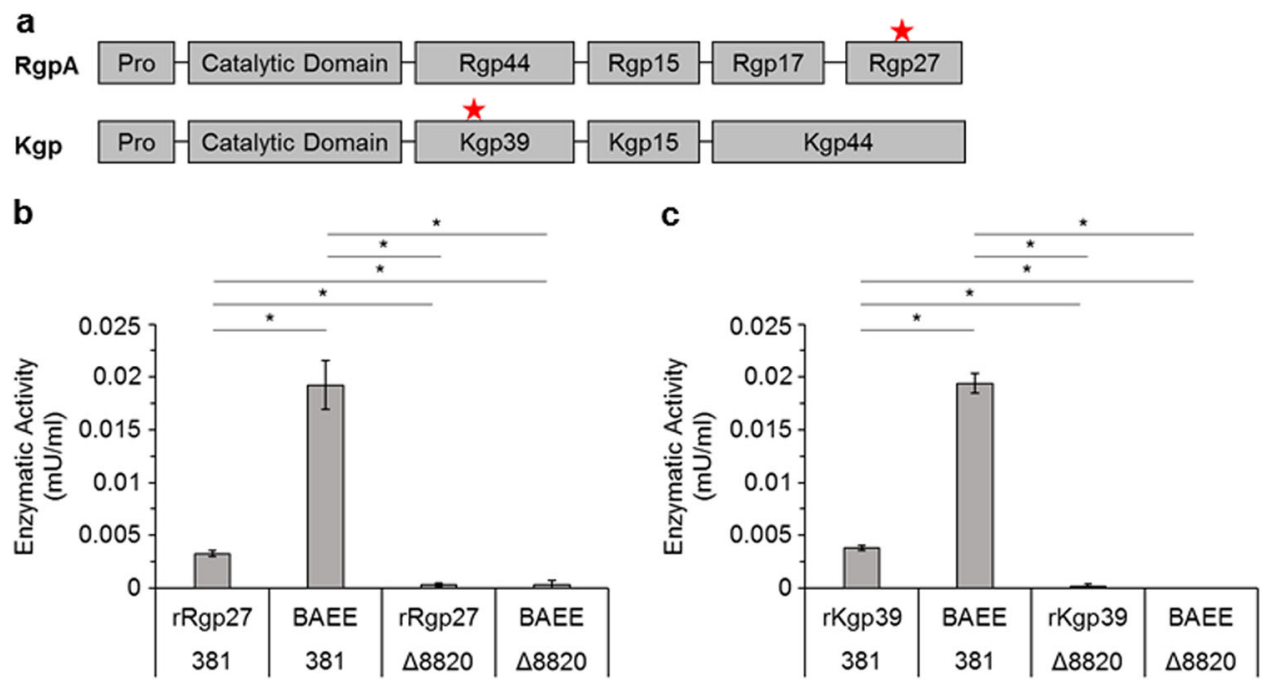

Fig. 5381 citrullinates gingipain-derived adhesin proteins. a 381 and $\Delta 8820$ cell lysates were analyzed by mass spectrometry to identify citrulline residues in 381. Mass spectrometry predicted a citrulline residue within adhesin domain Rgp27 of gingipain RgpA and within adhesin domain Kgp39 of gingipain Kgp (red stars). b, c Recombinant Rgp27 and Kgp39 were expressed in E. coli and then used as substrates in the PPAD enzymatic activity assay. 381 was able to citrullinate both b rRgp27 and c rkgp39 in vitro, whereas $\Delta 8820$ was unable to citrullinate rRgp27, rKgp39, or BAEE (positive control). Data in $\mathbf{b}$ and $\mathbf{c}$ are representative of two independent experiments showing similar results $(n=3)$. Error bars represent the standard deviation of technical replicates. The data were analyzed by ANOVA with Bonferroni post tests. ${ }^{*} p<0.05$

specifically within adhesin proteins Rgp27 and Kgp39 (Fig. 5a). However, using mass spectrometry to identify citrulline residues is difficult. Deamidation and citrullination both produce a $1 \mathrm{Da}$ shift; if a peptide contains both an asparagine or glutamine that can be deamidated and an arginine that can be citrullinated, it is not possible to determine which modification produced the shift. ${ }^{7}$ Therefore, to verify our mass spectrometry findings, we tested the ability of 381 to citrullinate these proteins in vitro. To perform these experiments, recombinant Rgp27 and Kgp39 (rRgp27 and rKgp39) were expressed in E. coli (Supplementary Figures 7 and 8) and used as substrates in a colorimetric assay that measures citrullination. Strain 381 was able to citrullinate both rRgp27 and rkgp39 at low levels, whereas, $\Delta 8820$ was unable to citrullinate rRgp27, rKgp39, or BAEE (Fig. 5b, c). Overall, although some of the previously identified PPAD targets were not detected in strain 381 under these growth conditions, our data support previous findings that $P$. gingivalis can citrullinate RgpA and Kgp and further shows that $P$. gingivalis can specifically citrullinate gingipain-derived adhesins in vitro.

PPAD mutant biofilms contain more gingipain-derived adhesin proteins that localize to the matrix

$P$. gingivalis strain 381 cultures expressing PPAD and, thereby, containing peptidylcitrulline formed less biofilm than $\Delta 8820$. Additionally, strain 381 citrullinated the gingipain-derived adhesin proteins, which play a central role in $P$. gingivalis attachment. ${ }^{37-39}$ Therefore, we hypothesized that 381 biofilms contain fewer adhesin proteins than $\Delta 8820$ biofilms. To test this, 381 and $\Delta 8820$ biofilm lysates were examined by western blot using an antiadhesin primary antibody (kindly provided by Dr. Mike Curtis, King's College London, London, UK). This anti-adhesin antibody was generated using the entire recombinant RgpA adhesin domain. The RgpA adhesin domain has high sequence similarity to the adhesin domain of Kgp, allowing the antibody to bind to all of the RgpA and Kgp adhesin proteins. ${ }^{38,40}$ Although a band corresponding to Rgp27 was not observed under the conditions tested, western blot analysis revealed bands corresponding to Rgp44 and Kgp39 in 381 and $\Delta 8820$ biofilm lysates (Fig. 6a). $\Delta 8820$ biofilm lysates contained more Rgp44 and, to a lesser extent, Kgp39 than 381 biofilm lysates (Fig. 6a, b). The planktonic cell fraction showed the opposite; 381 planktonic cell lysates contained more Rgp44 and Kgp39 than $\Delta 8820$ planktonic cell lysates (Fig. 6a, c). Overall, western blot analysis of 381 and $\Delta 8820$ showed that $\Delta 8820$ biofilms contained more gingipainderived adhesin proteins suggesting that citrullination of proteins that play a role in cell attachment modulates biofilm formation and development.

Because $\Delta 8820$ biofilms contain more gingipain-derived adhesin proteins and more matrix than 381 , we hypothesized that the gingipain-derived adhesin proteins are part of the biofilm matrix. To examine where adhesin proteins are localized, cells from 381 and $\Delta 8820$ colony biofilms were examined by TEM and scanning electron microscopy (SEM) followed by labeling with the primary anti-adhesin antibody and immunogold labeling. Immunogold labeling and TEM proved difficult due to a lack of contrast between the colloidal-gold-labeled secondary antibodies and the heavily stained extracellular aggregates. However, we could observe that anti-adhesin antibodies localized to the surface of the cells and to OMVs (Supplementary Figure 9). To supplement the TEM, we performed immunogold labeling and SEM, which does not require a negative stain. Under these conditions, we observed that gingipain-derived adhesin proteins primarily localized to the surface of 381 cells, while adhesins localized to $\Delta 8820$ cells and to matrix-like structures surrounding $\Delta 8820$ cells (Fig. 6d). Furthermore, gingipain-derived adhesin proteins localized to OMVs were more often observed in 381 than in $\Delta 8820$ (Supplementary Figure 10). Overall, our data indicate that $\Delta 8820$ biofilms have more matrix and the matrix contains more gingipain-derived adhesin proteins. Additionally, preliminary observations of fewer adhesin proteins in the OMV fractions of $\triangle 8820$ may suggest that OMVs, or improperly released OMVs containing adhesin proteins, in part, account for the accumulation of adhesin proteins in $\Delta 8820$ biofilms, but further work is required to support this working hypothesis.

Deletion of PPAD decreases secreted Rgp enzymatic activity and increases Rgp and Kgp enzymatic activity within biofilms Given that the adhesin domains are initially transcribed as part of precursor proteins, whether or not citrullination of the adhesin domains has an effect on gingipain activity was not clear. To test 
a

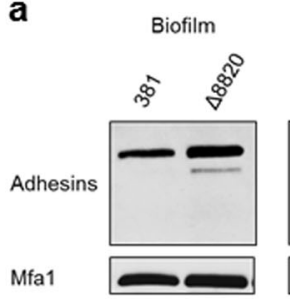

Planktonic
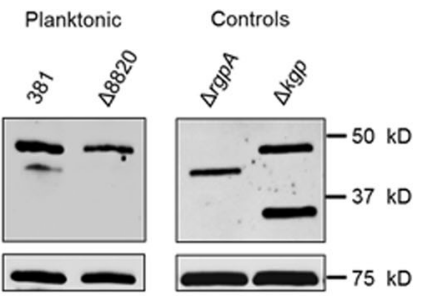

b

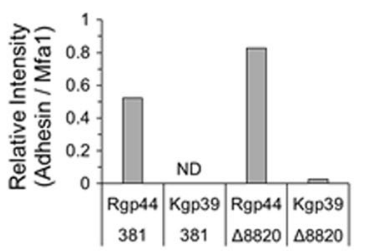

C

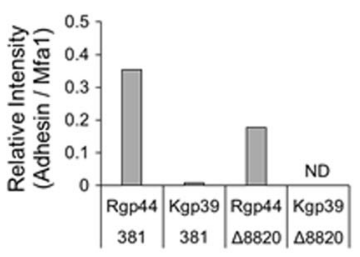

d
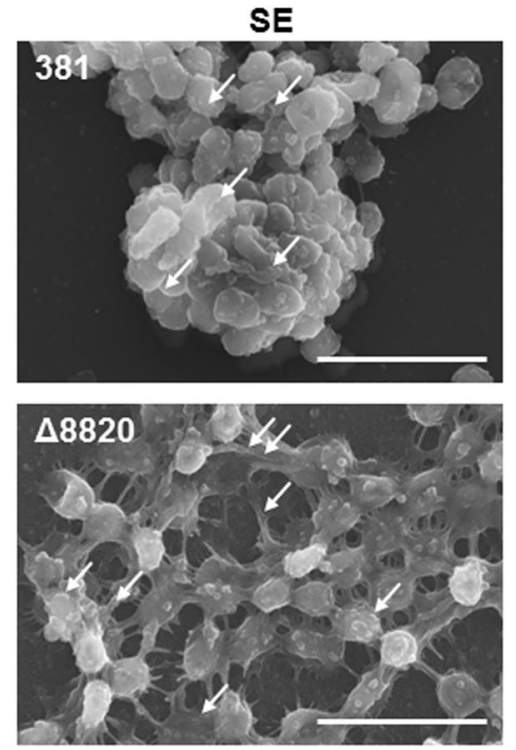

BSE
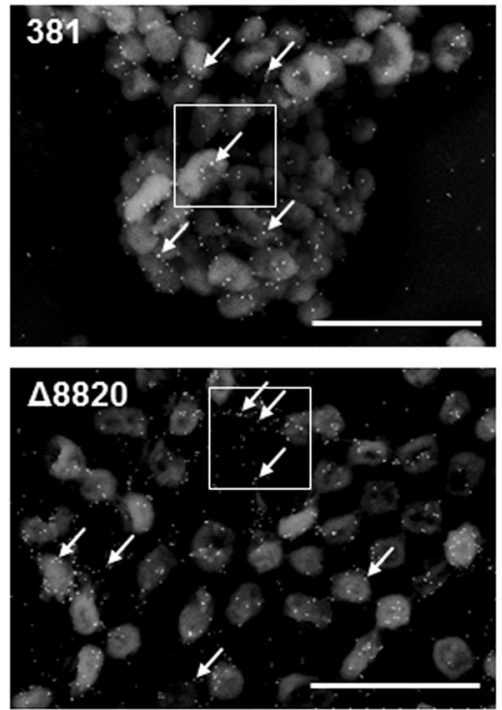

BSE
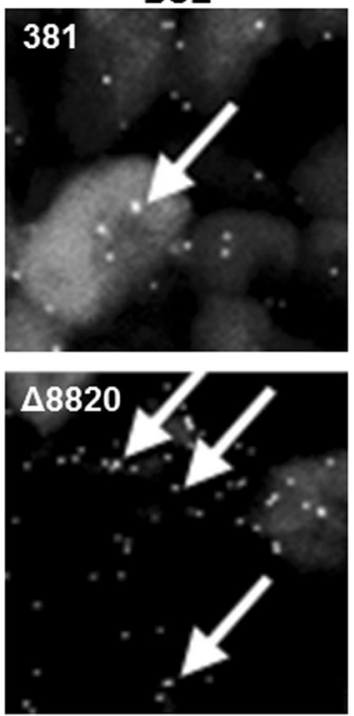

Fig. $6 \Delta 8820$ biofilms contain more gingipain-derived adhesin proteins than 381 biofilms. a Western blot analysis of biofilm lysates and planktonic cell lysates using an anti-adhesin primary antibody. $\triangle \operatorname{rgpA}$ and $\Delta \mathrm{kgp}$ planktonic cell lysates were used to determine the specific adhesin proteins (from top to bottom: Rgp44, Kgp39, Rgp27). Mfa1 was used as a loading control. All identified bands are shown. Samples derive from the same experiment and the blots were processed in parallel. b, c Quantification of b biofilm and $\mathbf{c}$ planktonic blots shown in $\mathbf{a}$. ND, none detected $\mathbf{d}$ Suspended 381 and $\Delta 8820$ colony biofilms were treated with the anti-adhesin primary antibody and then images were acquired by immunogold labeling and SEM. Gingipain-derived adhesin proteins localized to the surface of 381 cells, the surface of $\Delta 8820$ cells, and the matrix around $\Delta 8820$ cells. Arrows indicate representative colloidal gold particles. SE secondary electron, BSE ackscatter electron. Scale bar: $2 \mu \mathrm{m}$

the effect of deleting PPAD on gingipain enzymatic activity, we used a colorimetric assay to measure Rgp and Kgp enzymatic activity of 381 and $\Delta 8820$ planktonic cells, culture supernatants, and biofilm lysates. There was no difference in cell-associated Rgp activity between 381 and $\Delta 8820$, but the supernatant-associated Rgp activity was lower in $\Delta 8820$ than 381 (Fig. 7a). There was no difference in cell-associated or supernatant-associated Kgp activity between 381 and $\Delta 8820$ (Fig. 7b). However, there was greater Rgp and Kgp enzymatic activities in $\Delta 8820$ biofilm lysates than 381 biofilm lysates (Fig. 7c, d). Therefore, our data show that a lack of PPAD activity decreases the Rgp enzymatic activity in the supernatant while increasing the biofilm-associated Rgp and Kgp activities, indicating that citrullination determines whether these enzymes are retained in the biofilm or released.

\section{DISCUSSION}

$P$. gingivalis is an oral bacterium strongly implicated in the etiology of adult periodontal disease due, in part, to its ability to colonize and persist within the subgingival biofilm. 2,25,41,42 Identifying and understanding mechanisms that mediate cell attachment and surface attached growth is therefore of fundamental importance to understanding the pathogenic potential of $P$. gingivalis. Although studies have shown that $P$. gingivalis can citrullinate endogenous proteins, the effect of these citrullinated proteins on its physiology remains unclear. Here, we showed that deletion of the gene encoding PPAD prevented the citrullination of proteins, which enhanced biofilm formation in monoculture by enhancing cell-cell interactions, attachment, and matrix production. Surprisingly, this phenotype was not due to an increase in major or minor fimbriae on the cell surface, but instead due, at least in part, to the accumulation of gingipain-derived adhesin proteins within mutant biofilms. Overall, these findings support the model that PPAD modulates $P$. gingivalis biofilm formation in a hyperfimbriated strain via citrullination of secreted proteins known to play a role in attachment and biofilm development.

EM of $\Delta 8820$ colony biofilms revealed the presence of a profuse extracellular substance. We hypothesized that the extracellular substance was a component of the biofilm matrix of $\Delta 8820$ biofilms. EM analysis confirmed that gingipain-derived adhesin proteins localized to the cells and OMVs, as well as to the matrixlike substance. Therefore, the results suggest that these secreted protein aggregates are indeed a major component of the extracellular matrix. PPAD is secreted through the T9SS and can citrullinate other proteins secreted by the T9SS. Since PPAD normally citrullinates peptides or proteins including those that are secreted by the T9SS, it is likely that the observed extracellular fibers produced by $\Delta 8820$ are made up of proteins secreted by the T9SS, specifically proteins that normally rely on citrullination for normal folding, secretion, and/or localization to the cell-surface or to OMVs. Overall, further research is needed to identify the composition of the matrix produced by the PPAD null mutant.

Although fimbriae contain many arginine residues, mass spectrometry did not predict that fimbriae were citrullinated in 
a

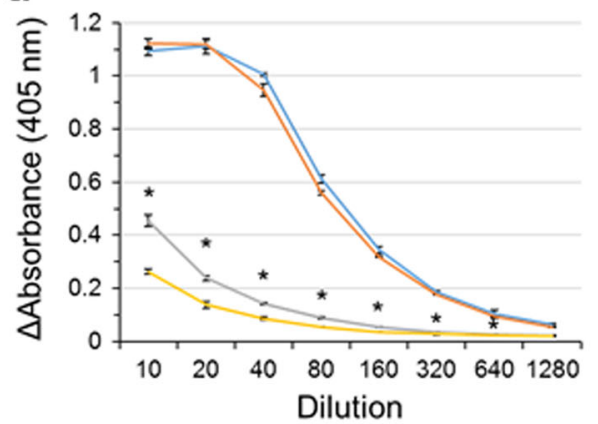

-381 Cells $-\Delta 8820$ Cells

-381 Sup $-\Delta 8820$ Sup

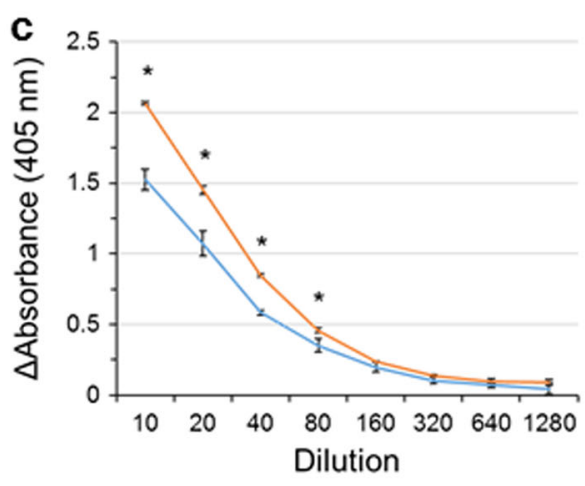

-381 Biofilm $-\triangle 8820$ Biofilm b

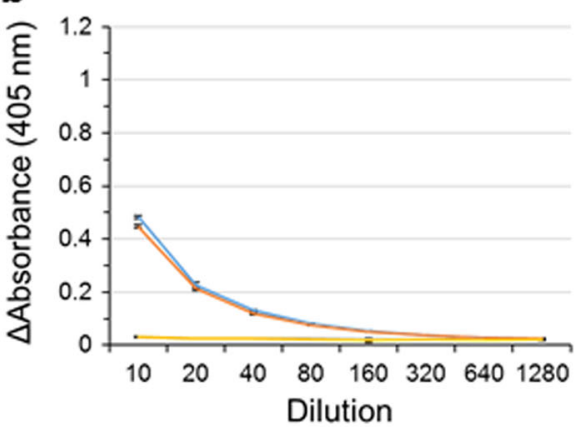

-381 Cells $-\Delta 8820$ Cells

-381 Sup $\quad \Delta 8820$ Sup

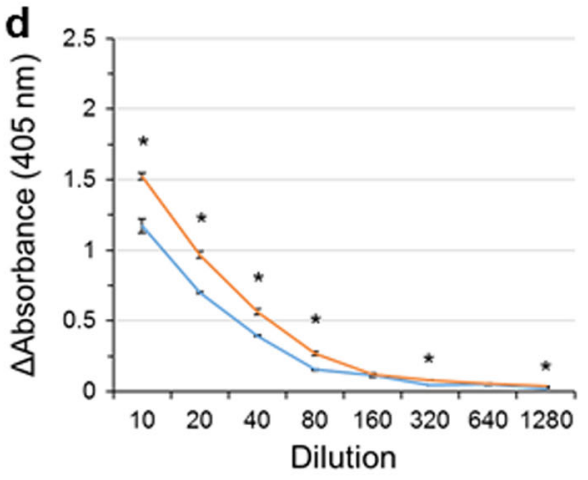

-381 Biofilm $-\Delta 8820$ Biofilm

Fig. 7 Deletion of PPAD decreases secreted Rgp enzymatic activity and increases Rgp and Kgp enzymatic activity in biofilms. Rgp enzymatic activity in a planktonic cultures and $\mathbf{c}$ biofilm lysates, and Kgp enzymatic activity in b planktonic culture and $\mathbf{d}$ biofilm lysates was measured using a colorimetric assay. a Less Rgp activity was measured in the supernatants of $\Delta 8820$ cultures. $\mathbf{b}$ There were no differences in Kgp activity between 381 and $\Delta 8820$. Both c Rgp and d Kgp enzymatic activities were greater in $\Delta 8820$ biofilm lysates than 381 biofilm lysates. Data are representative of three independent experiments showing similar results $(n=3)$. Error bars represent the standard deviation of technical replicates. The data were analyzed using the Student's two-tailed $t$-test. ${ }^{*} p<0.05$

strain 381 under the conditions tested; though, as noted above, identification of citrullinated proteins by mass spectrometry is technically challenging, so it is not yet clear if these surface structures are modified by PPAD. Stobernack et al. showed that a clinical isolate of $P$. gingivalis tentatively citrullinated FimA and confidently citrullinated Mfa1, but, similar to our findings, neither FimA nor Mfa1 were predicted to be citrullinated in lab strain ATCC $33277 .^{7}$ However, fimbriae can bind to arginine residues within proteins and peptides, including peptides that can be citrullinated by PPAD. ${ }^{20,43}$ Therefore, it is possible that even if PPAD does not citrullinate fimbriae directly in strain 381, the retention of positive arginine residues within fimbriae-associated proteins and/or peptides in the absence of PPAD may allow for a greater number of interactions with fimbriae that may in turn affect surface attachment, cell-cell interactions, and/or autoaggregation.

On the other hand, gingpains, primarily arginine gingipains (RgpA and RgpB), have long been associated with PPAD. Rgp deletion mutants have significantly fewer citrullinated proteins than their parent strains. ${ }^{5}$ This along with evidence showing that PPAD preferentially acts on C-terminal arginine residues supports the model that Rgp cleaves proteins at arginine residues thus freeing a C-terminal arginine residue for PPAD to citrullinate. That said, RgpA can also be citrullinated by PPAD.7 Our study supports previous findings that PPAD citrullinates RgpA and Kgp. Interestingly, our study and that of Stobernack et al. show that Rgp and $\mathrm{Kgp}$ are predicted to be citrullinated within adhesin domains, not the catalytic domain. ${ }^{7}$ Although citrullination of the catalytic domain of these gingipains was not detected in our study, Rgp and Kgp enzymatic activity was altered in the PPAD deletion mutant; $\Delta 8820$ produced less enzymatic activity than 381 by secreted Rgp in planktonic culture, while $\Delta 8820$ biofilms retained more Rgp and Kgp enzymatic activity than 381. It is known that the mature proteases can form complexes by non-covalently binding processed adhesin proteins. ${ }^{44}$ Therefore, the increase in gingipain activity in $\Delta 8820$ biofilm lysates may be due to the mature proteases binding to the positively charged adhesin proteins. Furthermore, we observed fewer adhesin proteins in $\triangle 8820$ OMV samples which, based on the dry weights of OMV preparations (unpublished data), may be due to fewer OMVs being released from the surface of the mutant cells. As a result of these findings, we posit that PPAD activity may affect the loading and/or release of OMVs and that in the absence of PPAD, OMVs and the proteins within those OMVs, including proteases and adhesin proteins, remain associated with the cell surface, promoting attachment and biofilm formation.

Expression of PPAD in strain $\mathrm{W} 50$ has been shown to be important for inducing alveolar bone loss in BALB/c mice, as well as in attachment and invasion of gingival fibroblasts by strain $33277 ;^{14,26}$ yet, our results show that deleting the gene that encodes PPAD in hyperfimbriated strain 381 enhances biofilm formation in monoculture. Hence, it is possible that by simply neutralizing certain charged arginine residues PPAD plays a central role in modulating colonization and pathogenesis of $P$. gingivalis, though the impact may vary depending on strain. Additionally, $P$. gingivalis is a member of the subgingival biofilm, which is comprised of several other bacterial species with which $P$. gingivalis can bind and interact. Recent publications have 
examined the role of PPAD in biofilm formation and interspecies, as well as interkingdom, interactions. One study, using ATCC 33277 , which is a close relative of strain 381 based on genome clustering analysis, determined that deletion of PPAD did not alter biofilm formation in a single species biofilm or in a multispecies system. ${ }^{45-47}$ In contrast, another study using the encapsulated strain W83, found that deletion of PPAD reduced binding of W83 to Candida albicans. ${ }^{48}$ In essence different $P$. gingivalis strains appear to exhibit distinct colonization and/or biofilm phenotypes when PPAD is deleted; however, it is important to note that the growth medium used was different in each of these studies. In addition, although the chromosomal gene order between ATCC 33277 and 381 is nearly identical, strain 381 is hyperfimbriated, resulting in a robust biofilm formation phenotype. In summary, it is clear that PPAD can impact colonization in different strains, yet additional studies with a variety of isolates under the same growth conditions is required to unravel the true impact of PPAD on the basic physiology of $P$. gingivalis.

In conclusion, in this study we determined that the unique prokaryotic PPAD has a significant impact on $P$. gingivalis strain 381 biofilm formation, a key feature of the bacterium's ability to persist and cause disease. It has been well established that $P$. gingivalis can citrullinate endogenous proteins and the results of our study demonstrate that citrullination of gingipain-derived adhesin domains limits their accumulation in and the formation of P. gingivalis biofilms. Further investigations into the role PPAD plays in $P$. gingivalis physiology will likely increase our understanding of the pathogenic potential of this pathobiont.

\section{METHODS}

Bacterial strains and culture conditions

Bacterial strains and plasmids used in this study are shown in Supplementary Table 1. P. gingivalis strain 381 (kindly provided by Dr. Howard Kuramitsu, State University of Buffalo, Buffalo, NY) and derivatives were grown on Trypticase Soy Agar plates supplemented with $5 \mu \mathrm{g} \mathrm{ml}^{-1}$ hemin, $1 \mu \mathrm{g} \mathrm{m}^{-1}$ menadione, and 5\% defibrinated sheep blood (BAPHK) (Northeast Laboratory Services) at $37^{\circ} \mathrm{C}$ in an anaerobic chamber (Coy Lab Products) with an atmosphere containing $5 \%$ hydrogen, $10 \%$ carbon dioxide, and $85 \%$ nitrogen. Planktonic cultures of $P$. gingivalis were grown in Todd Hewitt Broth (Becton, Dickinson and Company) supplemented with $5 \mu \mathrm{g} \mathrm{ml}^{-1}$ hemin and $1 \mu \mathrm{g} \mathrm{ml}^{-1}$ menadione (THBHK). P. gingivalis deletion mutants were maintained by supplementing media with $10 \mu \mathrm{g}$ $\mathrm{ml}^{-1}$ erythromycin. $P$. gingivalis strains harboring $\mathrm{pT}-\mathrm{COW}$ plasmids were maintained by supplementing media with $1 \mu \mathrm{g} \mathrm{ml}^{-1}$ tetracycline. For $P$. gingivalis strains grown as colony biofilms, $P$. gingivalis was grown anaerobically in THBHK for $24 \mathrm{~h}$ at $37{ }^{\circ} \mathrm{C}$, sub-cultured into pre-reduced THBHK, and grown overnight. Cultures were diluted to an $\mathrm{OD}_{600}$ of 1.0 , diluted 1:10, and then aliquots $(10 \mu \mathrm{l})$ were spotted onto BAPHK. Plates were grown anaerobically for 4-6 days. Escherichia coli strains were grown in Luria Broth (LB) (Thermo Fisher Scientific) or on LB agar plates at $37^{\circ} \mathrm{C}$. E. coli plasmid strains were maintained by supplementing the media with $100 \mu \mathrm{g} \mathrm{ml}^{-1}$ ampicillin.

\section{Construction and complementation of mutant strain}

Deletion and replacement of the entire coding region of the gene encoding PPAD (PGF_00008820) with ermF was achieved by generating an allelic replacement cassette with the NEBuilder HiFi DNA assembly cloning kit (New England BioLabs) using the instructions provided by the manufacturer, as previously described. ${ }^{49}$ All primers used in this study are presented in Supplementary Table 2. The PPAD deletion mutant $(\triangle 8820)$ was complemented in trans by inserting a functional copy of PGF_00008820 into plasmid pT-COW under the control of the low level, constitutive $P$. gingivalis groES promoter generating plasmid $\mathrm{pT}-\mathrm{C} 8820 .{ }^{50,51}$ Plasmid pT-C8820 was transformed into $\Delta 8820$ by electroporation. For control strains, plasmid pT-COW was transformed into both the parent strain 381 and $\Delta 8820$ mutant by electroporation.

\section{Growth and imaging of biofilms}

Biofilm assays in uncoated 96-well polystyrene plates were performed in a chemically defined media supplemented with $1 \%$ tryptone (CDM-T) as previously described. ${ }^{28}$ Fluorescent imaging was performed in the anaerobic chamber on biofilms grown on uncoated 12-well glass-bottom plates using the Invitrogen Live/Dead BacLight Bacterial Viability Kit (Thermo Thermo Fisher Scientific) and SYPRO Ruby Biofilm Matrix Stain (Thermo Thermo Fisher Scientific) as per the manufacturer's instructions. In brief, culture supernatants $(1 \mathrm{ml})$ were removed; wells were washed twice with distilled water; $1 \mathrm{ml}$ of Live/Dead stain (components A [SYTO 9] and B [propidium iodide] were mixed in equal volumes and $3 \mu$ were added per $1 \mathrm{ml}$ of distilled water), SYTO 9, or SYPRO Ruby Biofilm Matrix Stain was added to each well; and then the plate was incubated in the dark for $15 \mathrm{~min}$. The dye mixture was removed and water added to cover the base of the well. Images of biofilms stained with SYTO 9 and propidium iodided were acquired using a Nikon Eclipse Ti inverted fluorescence microscope setup inside the anaerobic chamber. SYTO 9 fluorescence was detected using the FITC bandpass filter cube. Propidium iodided fluorescence was detected using the Texas Red bandpass filter cube. Images of biofilms stained with SYTO 9 and SYPRO Ruby were acquired by confocal scanning laser microscopy (CLSM) using a spinning disk confocal system connected to a Leica DMIRB inverted fluorescence microscope equipped with a Photometrics cascade-cooled electron-multiplying CCD (EMCCD) camera. SYTO 9 fluorescence was detected by excitation at $488 \mathrm{~nm}$ and emission was collected using a $525-\mathrm{nm}$ bandpass filter. The detection of SYPRO Ruby was performed using a 642-nm excitation laser and a 695-nm bandpass filter. Images were acquired using the $\times 63$ objective. Stacked maximum intensity projection images were analyzed using Comstat2 version 2.1..$^{52}$

\section{Transmission electron microscopy (TEM)}

Forty microliters of $1 x$ PBS was placed on a single $P$. gingivalis colony biofilm and suspended. Poly-L-lysine treated, glow discharged, carboncoated Formvar 400 mesh copper grid was floated onto the suspended colony for $5 \mathrm{~min}$, followed by a quick water wash. Without letting the grid dry, the grid was floated onto a $10 \mu \mathrm{l}$ droplet of $4 \%$ paraformaldehyde for 5 min. Excess solution was dabbed off with filter paper and grid was floated on $0.5 \%$ aqueous uranyl acetate for $30 \mathrm{~s}$. Stain was removed with filter paper, air dried and examined with FEI Tecnai G2 Spirit Twin TEM (FEI Corp.) and digital images were acquired with Gatan UltraScan $2 k \times 2 k$ camera and Digital Micrograph software (Gatan Inc.).

\section{Cryo scanning electron microscopy}

Cryo-SEM experiments were performed using a Quorum PP3010T cryotransfer system (Quorum Technologies, Electron Microscopy Sciences) attached to a Hitachi SU5000FE VP-SEM (Hitachi High Technologies, America). Samples were prepared for Cryo-SEM by removal of the colony biofilm from blood agar substrate with a \#11 scalpel and mounted onto a specimen shuttle containing a carbon adhesive tab (Electron Microscopy Sciences) on an aluminum stub. The sample containing shuttle was attached to the PrepDek ${ }^{\circledR}$ workstation transfer rod device, plunge frozen in slushed liquid nitrogen at $-210{ }^{\circ} \mathrm{C}$ under vacuum and quickly transferred to the Cryo-preparation chamber. To remove any condensed ice from the surface gained during transfer, the sample temperature was raised to $-95^{\circ} \mathrm{C}$ and sublimed for $10 \mathrm{~min}$. To avoid charging artifacts and to render the sample conductive, a thin layer of platinum was sputter coated for $60 \mathrm{~s}$ at $10 \mathrm{~mA}$ current in an argon atmosphere at $-95^{\circ} \mathrm{C}$. The Cryo-prep chamber returned to $-195^{\circ} \mathrm{C}$, at a vacuum of $>10^{-5} \mathrm{mbar}$ and transferred to the nitrogen gas-cooled cold stage inside the SEM chamber. The sample remained frozen during the imaging at $-195^{\circ} \mathrm{C}$, under high vacuum conditions using 5-6 keV, current emission $176,000 \mathrm{nA}$, and working distance between 5 and $10 \mathrm{~mm}$.

\section{Mass spectrometry analysis}

$P$. gingivalis stationary-phase cultures were centrifuged, supernatant was removed, and cells were lysed in xTractor Buffer containing DNase I, lysozyme, and protease inhibitor (Takara Bio USA Inc.). Lysates were cleared by centrifugation at $12,000 \times \mathrm{g}$ for $20 \mathrm{~min}$ at $4{ }^{\circ} \mathrm{C}$ and protein concentration of cleared lysates was determined using the Pierce ${ }^{\mathrm{TM}} \mathrm{BCA}$ Protein Assay Kit (Thermo Fisher Scientific). Thirty micrograms of total protein was run on a $12 \%$ SDS-PAGE gel until the dye front was $5-10 \mathrm{~mm}$ down the resolving gel. The gel was stained with Bio-Safe Coomassie G- 
250 (BioRad) and the entirety of stained protein was carefully cut from the gel and then cut into 1-2 mm cubes.

For mass spectrometry analyses, the protein samples were solubilized and digested with trypsin. The digested peptides were desalted using micro ZipTip mini-reverse phase (Millipore). Peptides derived from the protein samples were resuspended in $0.1 \%$ formic acid for mass spectrometric analysis. The mass spectrometry data acquisition was performed on an EASY-nLC 1200 ultraperformance liquid chromatography system (Thermo Fisher Scientific) connected to an Orbitrap Q-Exactive Plus instrument equipped with a nano-electrospray source (Thermo Fisher Scientific). The peptide samples were loaded to a C18 trapping column $\left(75 \mu \mathrm{m}\right.$ i.d. $\times 2 \mathrm{~cm}$, Acclaim PepMap ${ }^{\circledR} 100$ particles with $3 \mu \mathrm{m}$ size and $100 \AA$ pores) and then eluted using a C18 analytical column (75 $\mu \mathrm{m}$ i.d. $\times$ $25 \mathrm{~cm}, 2 \mu \mathrm{m}$ particles with $100 \AA$ pore size). The flow rate was set at $250 \mathrm{~nL} /$ min with solvent $A(0.1 \%$ formic acid in water) and solvent $B(0.1 \%$ formic acid and $99.9 \%$ acetonitrile) as the mobile phases. Separation was conducted using a gradient and the full MS1 scan ( $\mathrm{m} / \mathrm{z} 350-1800)$ was performed on the Orbitrap with a resolution of 70,000 . The MS/MS was carried out in the Orbitrap, with a quadrupole isolation window of $1.3 \mathrm{Da}$. Fragmentation of the top 10 selected peptides by high-energy collision dissociation (HCD) was done at $27 \%$ of normalized collision energy. The MS2 spectra were acquired at a resolution of 17,500 and detected through Fourier transformation of image current with the AGC target as $5 \mathrm{e} 5$ and the maximum injection time as $50 \mathrm{~ms}$.

The tandem mass spectra were extracted from the Xcalibur.raw files and converted into mgf files using Proteome Discoverer 2.1 (Thermo Thermo Fisher Scientific). Charge state deconvolution and deisotoping were not performed. All MS/MS samples were analyzed using Mascot (Matrix Science, version 2.4.1). Mascot was set up to search the NCBInr_20130403 database (selected for Bacteria, unknown version, 14961948 entries) assuming the digestion enzyme trypsin. Mascot was searched with a fragment ion mass tolerance of $0.0100 \mathrm{Da}$ and a parent ion tolerance of 10.0 ppm. Carbamidomethyl of cysteine was specified in Mascot as a fixed modification. Gln $\rightarrow$ pyro-Glu of the $n$-terminus, deamidated asparagine and glutamine, oxidation of methionine, and deimination of arginine were specified in Mascot as variable modifications. Scaffold (Proteome Software Inc., version 4.2.1) was used to validate MS/MS-based peptide and protein identifications. Peptide identifications were accepted if they could be established at $>80 \%$ probability by the Peptide Prophet algorithm with Scaffold delta-mass correction. ${ }^{53}$ Protein identifications were accepted if they could be established at $>90 \%$ probability and contained at least one identified peptide. Protein probabilities were assigned by the Protein Prophet algorithm. ${ }^{54}$ Proteins that contained similar peptides and could not be differentiated based on MS/MS analysis alone were grouped to satisfy the principles of parsimony. Proteins sharing significant peptide evidence were grouped into clusters.

\section{Protein expression and purification}

The coding regions of RgpA adhesin domain Rgp27 and Kgp adhesin domain Kgp39 from P. gingivalis strain 381 were PCR amplified and cloned into pET-22b using the NEBuilder HiFi DNA assembly cloning kit (New England BioLabs) using the instructions provided by the manufacturer. Primers (Supplementary Table 2) were designed to incorporate sufficient overlapping regions at the ends of the products to permit the assembly of the Rgp27 or Kgp39 coding regions (inserts) with the PCR-linearized vector pET-22b. Products were generated using Phusion High-Fidelity PCR Master Mix with HF Buffer (New England BioLabs). The inserts were mixed 2:1 with the vector backbone and incubated with the NEB Assembly Master Mix according to the manufacturer's instructions. The assembled product was used to transform NEB 5 a chemically competent E. coli (New England BioLabs) thereby generating pET22b-Rgp27 and pET22b-Kgp39. The inserts were sequenced using $\mathrm{T7}$ forward and reverse primers. Verified plasmids were then transformed into $E$. coli strain BL21(DE3) (New England BioLabs).

E. coli strain BL21(DE3) containing pET22b-Rgp27 or pET22b-Kgp39 was grown in LB broth containing $100 \mathrm{\mu g} \mathrm{ml}^{-1}$ ampicillin at $37^{\circ} \mathrm{C}$ on a platform shaker at $250 \mathrm{rpm}$ until the cultures reached an $\mathrm{OD}_{600}$ of 1.0 . Cultures were then induced with IPTG at a final concentration of $1 \mathrm{mM}$ and grown for an additional $4 \mathrm{~h}$. Cells were then pelleted at $4700 \mathrm{rpm}$ for $5 \mathrm{~min}$. and the pellets were frozen at $-20^{\circ} \mathrm{C}$. To purify proteins, $8 \mathrm{ml}$ guanidinium lysis buffer $(6 \mathrm{M}$ guanidine hydrochloride, $500 \mathrm{mM} \mathrm{NaCl}, 20 \mathrm{mM}$ sodium phosphate $\mathrm{pH}$ 7.8) per $50 \mathrm{ml}$ culture pellet was added and cells were lysed by rocking for $10 \mathrm{~min}$ at room temperature. Cell lysate was sonicated on ice with three $5 \mathrm{~s}$ pulses at high intensity. Lysate was centrifuged at $3000 \times g$ for $15 \mathrm{~min}$ at $4^{\circ} \mathrm{C}$. Suspended HisPur Ni-NTA-agarose (Thermo
Thermo Fisher Scientific) was added to a Pierce ${ }^{\circledR}$ centrifuge column (Thermo Thermo Fisher Scientific). Once the resin settled, the supernatant was gently removed and the resin was washed once in sterile $\mathrm{dH}_{2} \mathrm{O}$ then equilibrated twice in denaturing binding buffer $(8 \mathrm{M}$ urea, $500 \mathrm{mM} \mathrm{NaCl}$ $20 \mathrm{mM}$ sodium phosphate $\mathrm{pH} 7.8$ ). Lysate was transferred to the prepared purification column and incubated for $30 \mathrm{~min}$ at room temperature with rocking. The column was washed two times with denaturing binding buffer for $2 \mathrm{~min}$. The column was then washed two times with denaturing wash buffer ( $8 \mathrm{M}$ urea, $500 \mathrm{mM} \mathrm{NaCl}, 20 \mathrm{mM}$ sodium phosphate $\mathrm{pH} 6.0$ ) for $2 \mathrm{~min}$ followed by washing four times with native wash buffer $(20 \mathrm{mM}$ imidazole, $0.5 \mathrm{M} \mathrm{NaCl}, 50 \mathrm{mM} \mathrm{NaH} \mathrm{PO}_{4} \mathrm{pH} 8.0$ ) for $2 \mathrm{~min}$. Ni-bound protein was eluted with native elution buffer $(250 \mathrm{mM}$ imidazole, $0.5 \mathrm{M} \mathrm{NaCl}$, $50 \mathrm{mM} \mathrm{NaH} \mathrm{PO}_{4} \mathrm{pH}$ 8.0). Proteins were dialyzed overnight in $0.1 \mathrm{M} \mathrm{Tris} / \mathrm{HCl}$ (pH 7.5) containing $10 \%$ glycerol. Proteins were stored at $-20^{\circ} \mathrm{C}$.

\section{PPAD enzymatic activity}

Stationary-phase cultures were diluted to the same $\mathrm{OD}_{600}$ and the PPAD enzymatic activity assay was setup in a 96-well PCR plate (Bio-Rad Laboratories, Inc.) and measured as previously described. ${ }^{55}$ In brief, $10 \mu \mathrm{l}$ of culture was added to $35 \mu \mathrm{l}$ incubation buffer $(0.1 \mathrm{M}$ Tris- $\mathrm{HCl}$ buffer [pH 7.5] and $5 \mathrm{mM}$ DTT) for experimental wells or $40 \mu \mathrm{l}$ incubation buffer for control wells. $5 \mu \mathrm{l}$ of substrate (BAEE or L-arginine) was added to each experimental well to a final concentration of $5 \mathrm{mM}$. $5 \mu$ l of substrate was added to $45 \mu \mathrm{l}$ incubation buffer for substrate only controls. The plate was incubated at $37^{\circ} \mathrm{C}$ in a thermocycler for $30 \mathrm{~min} .150 \mu \mathrm{l}$ of freshly prepared citrulline detection reagent (1 volume of solution A $[80 \mathrm{mM} \mathrm{2,3-}$ butanedione monoxime and $2 \mathrm{mM}$ thiosemicarbazide] and 3 volumes of solution $\mathrm{B}\left[3 \mathrm{M} \mathrm{H}_{3} \mathrm{PO}_{4}, 6 \mathrm{M} \mathrm{H}_{2} \mathrm{SO}_{4}\right.$, and $\left.2 \mathrm{mM} \mathrm{NH}_{4} \mathrm{Fe}\left(\mathrm{SO}_{4}\right)_{2} \cdot 12 \mathrm{H}_{2} \mathrm{O}\right]$ ) was added to each well, then the plate was incubated at $95^{\circ} \mathrm{C}$ in a thermocycler for $15 \mathrm{~min}$. The samples were then transferred to a 96-well flat-bottom plate (Corning, Inc.) and enzymatically produced citrulline was detected at an absorbance of $540 \mathrm{~nm}$.

To test the ability of $P$. gingivalis to citrullinate rRgp27 and rKgp39, the following modifications were made to the above protocol. Stationary cultures were centrifuged and pellets were re-suspended to an $\mathrm{OD}_{600}$ of 1.0 in incubation buffer. rRgp27, rKgp39, and BAEE (positive control) were diluted to $0.15 \mathrm{mg} \mathrm{ml}^{-1}$ in incubation buffer. $11 \mu \mathrm{l}$ of $P$. gingivalis was added to $11 \mu \mathrm{l}$ of incubation buffer (negative control), rRgp27, rKgp39, or BAEE (positive control) per well of a 96-well PCR plate. $11 \mu \mathrm{l}$ rRgp27, rKgp39, or BAEE was added to $11 \mu \mathrm{l}$ incubation buffer as substrate only controls. The plate was sealed and incubated at $37^{\circ} \mathrm{C}$ in a thermocycler for $1 \mathrm{~h}$. After incubation, the seal was removed and $66 \mu \mathrm{l}$ of freshly prepared citrulline detection reagent was added to each well.

\section{Immunoblots}

For planktonic samples, $P$. gingivalis was grown in THBHK for $24 \mathrm{~h}$, subcultured into pre-reduced THBHK, and grown to early exponential, midexponential, late exponential, and stationary phases. Cells were centrifuged, supernatant was removed, and cells were resuspended to a final $\mathrm{OD}_{600}$ of 1.0 in $\mathrm{dH}_{2} \mathrm{O}$. For biofilm samples, $24 \mathrm{~h}$ biofilms were washed twice in $\mathrm{dH}_{2} \mathrm{O}$ and then lysed with scraping in xTractor Buffer containing DNase I, lysozyme, and protease inhibitor (Takara Bio USA Inc.). Lysates were cleared by centrifugation at $12,000 \times \mathrm{g}$ for $20 \mathrm{~min}$ at $4{ }^{\circ} \mathrm{C}$ and protein concentration of cleared lysates was determined using the Pierce ${ }^{\mathrm{TM}} \mathrm{BCA}$ Protein Assay Kit (Thermo Fisher Scientific). Planktonic or biofilm samples were mixed with $2 X$ SDS sample buffer and denatured by heating at $100^{\circ} \mathrm{C}$ for $5 \mathrm{~min}$. Planktonic samples $(10 \mu \mathrm{l})$ or biofilm samples $(5 \mu \mathrm{g})$ were then electrophoresed on a $12 \%$ polyacrylamide SDS-PAGE gel. For western blot analysis, proteins were transferred to a nitrocellulose membrane. The membrane was washed once for $5 \mathrm{~min}$ in TBS containing $0.1 \%$ Tween 20 (TBS-T) then blocked for $1 \mathrm{~h}$ in $5 \%$ milk in TBS-T with rocking at room temperature. Primary anti-FimA (kindly provided by Dr. Ashu Sharma, University of Buffalo, Buffalo, New York), anti-Mfa1 (kindly provided by Dr. Richard Lamont, University of Louisville, Louisville, Kentucky), or antiadhesin (kindly provided by Dr. Mike Curtis, King's College London, London, UK) antiserum was added 1:5000, 1:10,000, or 1:500, respectively, and incubated with the membrane for $1 \mathrm{~h}$ with rocking at room temperature. After washing the membrane in TBS-T for 5 min three times, the membrane was incubated with peroxidase-conjugated anti-rabbit lgG antibody at a dilution of 1:2000 for $1 \mathrm{~h}$ with rocking at room temperature. The membrane was washed three times in TBS-T for $5 \mathrm{~min}$ before detecting bands using SuperSignal ${ }^{R}$ West Pico Chemiluminescent 
Substrate (Thermo Fisher Scientific). Bands were quantified by measuring the band intensity in Image Lab version 5.2.1.

Previous experiments showed that the anti-FimA and anti-Mfa1 antibodies are specific and hybridized to proteins at 40 and $75 \mathrm{kDa}$, respectively. Occasionally it was observed that with increasing exposure time anti-Mfa1 hybridized to proteins below $75 \mathrm{kDa}$ and above $50 \mathrm{kDa}$ (Supplementary Figure 3). Since these antibodies were well established to be specific, a single membrane was cut between the $75 \mathrm{kDa}$ and the 50 $\mathrm{kDa}$ marker bands. The upper portion of the membrane was probed with the anti-Mfa1 antibody while the lower portion was probed with the antiFimA antibody. For experiments using the anti-adhesin antibody, it is known that this antibody binds to multiple bands corresponding to the various gingipain-derived adhesin proteins. The anti-adhesin antibody did not bind to proteins above $50 \mathrm{kDa}$ under the conditions tested. Therefore, a single membrane was cut between the $75 \mathrm{kDa}$ and the $50 \mathrm{kDa}$ marker bands. The upper portion of the membrane was probed with the anti-Mfa1 antibody as a loading control while the lower portion was probed with the anti-adhesin antibody. All bands identified by probing with the antiadhesin antibody are shown.

\section{Scanning electron microscopy (SEM)}

Cells from colony biofilms were collected from blood agar plates with $4 \%$ paraformaldehyde in $1 \mathrm{X}$ PBS, pH 7.24. Fixed cells were processed with the aid of a Pelco BioWave Pro laboratory microwave. The cells were deposited onto poly-L-lysine treated $13 \mathrm{~mm}$ Thermanox plastic coverslips, rinsed in PBS, and incubated for 20 min on blocking solution (1\% non-fat dry milk, $0.5 \%$ cold water fish skin gelatin, $0.01 \%$ Tween- 20 in PBS [pH 7.2]). After a PBS wash, the Thermanox coverslip containing cells was incubated for $1 \mathrm{~h}$ at room temperature with primary antibody at a dilution of 1:200, washed with PBS three times, and incubated for $1 \mathrm{~h}$ with $18 \mathrm{~nm}$ colloidal goldconjugated goat-anti-rabbit IgG diluted 1:20 (Jackson ImmunoResearch). Subsequently, washed with PBS, fixed with $2 \%$ glutaraldehyde, washed with water, and dehydrated in a graded ethanol series $(25 \%, 50 \%, 75 \%$, $95 \%, 100 \%)$ and critical point dried. Thermanox coverslip were mounted onto carbon adhesive tabs on aluminum specimen mount and carbon coated (Cressington 328/308R). Secondary electron (SE) and backscatter electron (BSE) digital micrographs were acquired using SEM (SU5000 VPSEM, Hitachi High-Technologies, America).

\section{Gingipain assay}

The activity of arginine and lysine gingipains was assessed as previously described. ${ }^{56}$ Briefly, $P$. gingivalis was grown anaerobically in THBHK for $24 \mathrm{~h}$. Cultures were either diluted into pre-reduced THBHK and grown to mid-exponential phase or diluted into CDM-T and grown in a polystyrene flat-bottom plate for $24 \mathrm{~h}$. Planktonic cultures were then normalized to an $\mathrm{OD}_{600}$ of 1.0 and $1 \mathrm{ml}$ of each culture centrifuged to pellet the cells. The supernatants were transferred to a separate tube while the pellets were resuspended in assay buffer $(200 \mathrm{mM}$ Tris, $5 \mathrm{mM} \mathrm{CaCl} 2,150 \mathrm{mM} \mathrm{NaCl}$, and $10 \mathrm{mM}$ L-cysteine at $\mathrm{pH}$ 7.6). $24 \mathrm{~h}$ biofilms were washed twice in $\mathrm{dH}_{2} \mathrm{O}$ and then lysed with scraping in xTractor Buffer containing DNase I, lysozyme, and protease inhibitor (Takara Bio USA Inc.). Lysates were cleared by centrifugation at $12,000 \times \mathrm{g}$ for $20 \mathrm{~min}$ at $4{ }^{\circ} \mathrm{C}$ and protein concentration of cleared lysates was determined using the Pierce ${ }^{\mathrm{TM}}$ BCA Protein Assay Kit (Thermo Fisher Scientific). Biofilm lysates were normalized to a protein concentration of $5 \mu \mathrm{g} \mu \mathrm{l}^{-1}$. Cells, supernatants, or biofilm lysates were diluted 1:10 in assay buffer and then serially diluted in assay buffer across a 96-well microtiter plate. The initial absorbance at $405 \mathrm{~nm}$ was measured and the plates were then incubated at $37^{\circ} \mathrm{C}$ for $10 \mathrm{~min}$ to equilibrate the temperature. $\mathrm{N}$-a-benzoyl-L-arginine-p-nitroanilide (BAPNA) or $\mathrm{N}$-a-acetylL-lysine-p-nitroanilide (ALPNA) was added to the wells at a final concentration of $1 \mathrm{mM}$ and the microtiter plates were incubated for $2 \mathrm{~h}$ at $37^{\circ} \mathrm{C}$. The final absorbance $\left(A_{405}\right)$ of the wells was recorded and the difference between the initial and final absorbance was determined.

\section{Reporting summary}

Further information on experimental design is available in the Nature Research Reporting Summary linked to this article.

\section{DATA AVAILABILITY}

The authors declare that the data supporting the findings of this study are available within the paper and its supplementary information files or from the corresponding author upon request.

\section{ACKNOWLEDGEMENTS}

We would like to thank the personnel at the University of Florida, Interdisciplinary Center for Biotechnology Research, Mass Spectrometry Core and at the University of Florida, Interdisciplinary Center for Biotechnology Research, Electron Microscopy Core for their expertise, especially, Karen Kelley of the Electron Microscopy Core. We would also like to thank all members of the Davey laboratory for many helpful discussions. This work was supported by the National Institute of Dental and Craniofacial Research of the National Institutes of Health under award numbers R01DEO24580 and R01DE019117 awarded to M.E.D. and award numbers T90DE021990 and F31DE027278 awarded to D.M.V.

\section{AUTHOR CONTRIBUTIONS}

D.M.V. contributed to the conception, experimental design, data acquisition, interpretation of data, and manuscript preparation. G.K.O. contributed to data acquisition, protein purification, and fluorescence microscopy. M.E.D. contributed to the conception, experimental design, interpretation of data, and editing the manuscript.

\section{ADDITIONAL INFORMATION}

Supplementary information accompanies the paper on the npj Biofilms and Microbiomes website (https://doi.org/10.1038/s41522-019-0081-x).

Competing interests: The authors declare no competing interests.

Publisher's note: Springer Nature remains neutral with regard to jurisdictional claims in published maps and institutional affiliations.

\section{REFERENCES}

1. de Pablo, P., Chapple, I. L., Buckley, C. D. \& Dietrich, T. Periodontitis in systemic rheumatic diseases. Nat. Rev. Rheumatol. 5, 218-224 (2009).

2. Hajishengallis, G. Periodontitis: from microbial immune subversion to systemic inflammation. Nat. Rev. Immunol. 15, 30-44 (2015).

3. Potempa, J., Mydel, P. \& Koziel, J. The case for periodontitis in the pathogenesis of rheumatoid arthritis. Nat. Rev. Rheumatol., https://doi.org/10.1038/ nrrheum.2017.132 (2017).

4. McGraw, W. T., Potempa, J., Farley, D. \& Travis, J. Purification, characterization, and sequence analysis of a potential virulence factor from Porphyromonas gingivalis, peptidylarginine deiminase. Infect. Immun. 67, 3248-3256 (1999).

5. Wegner, N. et al. Peptidylarginine deiminase from Porphyromonas gingivalis citrullinates human fibrinogen and a-enolase: implications for autoimmunity in rheumatoid arthritis. Arthritis Rheum. 62, 2662-2672 (2010).

6. Gabarrini, G. et al. The peptidylarginine deiminase gene is a conserved feature of Porphyromonas gingivalis. Sci. Rep. 5, 13936 (2015).

7. Stobernack, T. et al. The extracellular proteome and citrullinome of the oral pathogen Porphyromonas gingivalis. J. Proteome Res. https://doi.org/10.1021/acs. jproteome.6b00634 (2016).

8. Gabarrini, G. et al. Conserved citrullinating exoenzymes in Porphyromonas species. J. Dent. Res. 22034517747575, https://doi.org/10.1177/0022034517747575 (2017).

9. Vossenaar, E. R., Zendman, A. J., van Venrooij, W. J. \& Pruijn, G. J. PAD, a growing family of citrullinating enzymes: genes, features and involvement in disease. Bioessays 25, 1106-1118 (2003).

10. Bicker, K. L. \& Thompson, P. R. The protein arginine deiminases: structure, function, inhibition, and disease. Biopolymers 99, 155-163 (2013).

11. Wang, S. \& Wang, Y. Peptidylarginine deiminases in citrullination, gene regulation, health and pathogenesis. Biochim. Biophys. Acta 1829, 1126-1135 (2013).

12. Witalison, E. E., Thompson, P. R. \& Hofseth, L. J. Protein arginine deiminases and associated citrullination: physiological functions and diseases associated with dysregulation. Curr. Drug Targets 16, 700-710 (2015).

13. Maresz, K. J. et al. Porphyromonas gingivalis facilitates the development and progression of destructive arthritis through its unique bacterial peptidylarginine deiminase (PAD). PLoS Pathog. 9, e1003627 (2013). 
14. Gully, N. et al. Porphyromonas gingivalis peptidylarginine deiminase, a key contributor in the pathogenesis of experimental periodontal disease and experimental arthritis. PLoS One 9, e100838 (2014).

15. Koziel, J., Mydel, P. \& Potempa, J. The link between periodontal disease and rheumatoid arthritis: an updated review. Curr. Rheumatol. Rep. 16, 408 (2014).

16. Quirke, A. M. et al. Heightened immune response to autocitrullinated Porphyromonas gingivalis peptidylarginine deiminase: a potential mechanism for breaching immunologic tolerance in rheumatoid arthritis. Ann. Rheum. Dis. 73 263-269 (2014)

17. Montgomery, A. B. et al. Crystal structure of Porphyromonas gingivalis peptidylarginine deiminase: implications for autoimmunity in rheumatoid arthritis. Ann. Rheum. Dis. 75, 1255-1261 (2016)

18. Nakayama, K. Porphyromonas gingivalis and related bacteria: from colonial pigmentation to the type IX secretion system and gliding motility. J. Periodontal Res. 50, 1-8 (2015)

19. Goulas, T. et al. Structure and mechanism of a bacterial host-protein citrullinating virulence factor, Porphyromonas gingivalis peptidylarginine deiminase. Sci. Rep. $\mathbf{5}$ 11969 (2015).

20. Abdullah, S. N., Farmer, E. A., Spargo, L., Logan, R. \& Gully, N. Porphyromonas gingivalis peptidylarginine deiminase substrate specificity. Anaerobe 23, 102-108 (2013).

21. Moelants, E. A. et al. Citrullination and proteolytic processing of chemokines by Porphyromonas gingivalis. Infect. Immun. 82, 2511-2519 (2014).

22. Rodríguez, S. B., Stitt, B. L. \& Ash, D. E. Cysteine 351 is an essential nucleophile in catalysis by Porphyromonas gingivalis peptidylarginine deiminase. Arch. Biochem. Biophys. 504, 190-196 (2010).

23. Rodríguez, S. B., Stitt, B. L. \& Ash, D. E. Expression of peptidylarginine deiminase from Porphyromonas gingivalis in Escherichia coli: enzyme purification and characterization. Arch. Biochem. Biophys. 488, 14-22 (2009).

24. Shirai, H., Mokrab, Y. \& Mizuguchi, K. The guanidino-group modifying enzymes: structural basis for their diversity and commonality. Proteins 64, 1010-1023 (2006).

25. Takahashi, N. Oral microbiome metabolism: from "who are they?" to "what are they doing?". J. Dent. Res. 94, 1628-1637 (2015).

26. Gawron, K. et al. Peptidylarginine deiminase from Porphyromonas gingivalis contributes to infection of gingival fibroblasts and induction of prostaglandin E2 -signaling pathway. Mol. Oral Microbiol. 29, 321-332 (2014).

27. Xie, H., Lin, X., Wang, B. Y., Wu, J. \& Lamont, R. J. Identification of a signalling molecule involved in bacterial intergeneric communication. Microbiology 153 3228-3234 (2007).

28. Christopher, A. B., Arndt, A., Cugini, C. \& Davey, M. E. A streptococcal effector protein that inhibits Porphyromonas gingivalis biofilm development. Microbiology 156, 3469-3477 (2010)

29. Cugini, C., Stephens, D. N., Nguyen, D., Kantarci, A. \& Davey, M. E. Arginine deiminase inhibits Porphyromonas gingivalis surface attachment. Microbiology 159, 275-285 (2013).

30. Hamada, N. et al. Construction and characterization of a fimA mutant of Porphyromonas gingivalis. Infect. Immun. 62, 1696-1704 (1994).

31. Njoroge, T., Genco, R. J., Sojar, H. T., Hamada, N. \& Genco, C. A. A role for fimbriae in Porphyromonas gingivalis invasion of oral epithelial cells. Infect. Immun. 65, 1980-1984 (1997).

32. Weinberg, A., Belton, C. M., Park, Y. \& Lamont, R. J. Role of fimbriae in Porphyromonas gingivalis invasion of gingival epithelial cells. Infect. Immun. 65, 313-316 (1997).

33. Lin, X., Wu, J. \& Xie, H. Porphyromonas gingivalis minor fimbriae are required for cell-cell interactions. Infect. Immun. 74, 6011-6015 (2006).

34. Kuboniwa, M. et al. Distinct roles of long/short fimbriae and gingipains in homotypic biofilm development by Porphyromonas gingivalis. BMC Microbiol. 9, 105 (2009).

35. Veith, P. D. et al. Major outer membrane proteins and proteolytic processing of RgpA and Kgp of Porphyromonas gingivalis W50. Biochem. J. 363, 105-115 (2002)

36. Potempa, J., Pike, R. \& Travis, J. The multiple forms of trypsin-like activity present in various strains of Porphyromonas gingivalis are due to the presence of either Arg-gingipain or Lys-gingipain. Infect. Immun. 63, 1176-1182 (1995).

37. Bhogal, P. S., Slakeski, N. \& Reynolds, E. C. A cell-associated protein complex of Porphyromonas gingivalis W50 composed of Arg- and Lys-specific cysteine proteinases and adhesins. Microbiology 143, 2485-2495 (1997).

38. Chen, T., Nakayama, K., Belliveau, L. \& Duncan, M. J. Porphyromonas gingivalis gingipains and adhesion to epithelial cells. Infect. Immun. 69, 3048-3056 (2001).
39. Chen, T. \& Duncan, M. J. Gingipain adhesin domains mediate Porphyromonas gingivalis adherence to epithelial cells. Microb. Pathog. 36, 205-209 (2004).

40. Aduse-Opoku, J. et al. Generation of lys-gingipain protease activity in Porphyromonas gingivalis W50 is independent of Arg-gingipain protease activities. Microbiology 146, 1933-1940 (2000). (Pt 8).

41. Berezow, A. B. \& Darveau, R. P. Microbial shift and periodontitis. Periodontol 2000 55, 36-47 (2011).

42. Socransky, S. S. \& Haffajee, A. D. Periodontal microbial ecology. Periodontol 2000 38, 135-187 (2005)

43. Kontani, M., Kimura, S., Nakagawa, I. \& Hamada, S. Adherence of Porphyromonas gingivalis to matrix proteins via a fimbrial cryptic receptor exposed by its own arginine-specific protease. Mol. Microbiol. 24, 1179-1187 (1997).

44. Sato, K. et al. Identification of a new membrane-associated protein that influences transport/maturation of gingipains and adhesins of Porphyromonas gingivalis. J. Biol. Chem. 280, 8668-8677 (2005).

45. Aliko, A. et al. Impact of Porphyromonas gingivalis peptidylarginine deiminase on bacterial biofilm formation, epithelial cell invasion, and epithelial cell transcriptional landscape. Sci. Rep. 8, 14144 (2018).

46. Chastain-Gross, R. P. et al. Genome sequence of Porphyromonas gingivalis Strain 381. Genome Announc. 5, e01467-16 (2017).

47. Chen, T., Siddiqui, H. \& Olsen, I. In silico comparison of 19 Porphyromonas gingivalis strains in genomics, phylogenetics, phylogenomics and functional genomics. Front. Cell. Infect. Microbiol. 7, 28 (2017).

48. Karkowska-Kuleta, J. et al. The activity of bacterial peptidylarginine deiminase is important during formation of dual-species biofilm by periodontal pathogen Porphyromonas gingivalis and opportunistic fungus Candida albicans. Pathog. Dis. 76, fty033 (2018)

49. Moye, Z. D., Valiuskyte, K., Dewhirst, F. E., Nichols, F. C. \& Davey, M. E. Synthesis of sphingolipids impacts survival of Porphyromonas gingivalis and the presentation of surface polysaccharides. Front. Microbiol. 7, 1919 (2016).

50. Gardner, R. G., Russell, J. B., Wilson, D. B., Wang, G. R. \& Shoemaker, N. B. Use of a modified Bacteroides-Prevotella shuttle vector to transfer a reconstructed beta1,4-D-endoglucanase gene into Bacteroides uniformis and Prevotella ruminicola B (1)4. Appl. Environ. Microbiol. 62, 196-202 (1996).

51. Alberti-Segui, C., Arndt, A., Cugini, C., Priyadarshini, R. \& Davey, M. E. HU protein affects transcription of surface polysaccharide synthesis genes in Porphyromonas gingivalis. J. Bacteriol. 192, 6217-6229 (2010).

52. Heydorn, A. et al. Quantification of biofilm structures by the novel computer program COMSTAT. Microbiology 146, 2395-2407 (2000). (Pt 10).

53. Keller, A., Nesvizhskii, A. I., Kolker, E. \& Aebersold, R. Empirical statistical model to estimate the accuracy of peptide identifications made by MS/MS and database search. Anal. Chem. 74, 5383-5392 (2002).

54. Nesvizhskii, A. I., Keller, A., Kolker, E. \& Aebersold, R. A statistical model for identifying proteins by tandem mass spectrometry. Anal. Chem. 75, 4646-4658 (2003).

55. Knipp, M. \& Vasák, M. A colorimetric 96-well microtiter plate assay for the determination of enzymatically formed citrulline. Anal. Biochem. 286, 257-264 (2000)

56. Veillard, F., Potempa, B., Poreba, M., Drag, M. \& Potempa, J. Gingipain aminopeptidase activities in Porphyromonas gingivalis. Biol. Chem. 393, 1471-1476 (2012).

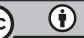

Open Access This article is licensed under a Creative Commons Attribution 4.0 International License, which permits use, sharing, adaptation, distribution and reproduction in any medium or format, as long as you give appropriate credit to the original author(s) and the source, provide a link to the Creative Commons license, and indicate if changes were made. The images or other third party material in this article are included in the article's Creative Commons license, unless indicated otherwise in a credit line to the material. If material is not included in the article's Creative Commons license and your intended use is not permitted by statutory regulation or exceeds the permitted use, you will need to obtain permission directly from the copyright holder. To view a copy of this license, visit http://creativecommons. org/licenses/by/4.0/.

(c) The Author(s) 2019 